\title{
Prophylactic use of Tranexamic Acid during Caesarean Section in Preventing Postpartum haemorrhage- a Prospective Randomised Double Blind Placebo Controlled Study
}

\author{
NAZLIMA NARGIS ${ }^{1}$, FARHANA DEWAN²
}

\begin{abstract}
Background: Postpartum haemorrhage (PPH) is a major cause of maternal mortality, accounting for one-quarter of all maternal deaths worldwide. Tranexamic acid (TXA), an antifibrinolytic agent, has therefore been investigated as a potentially useful complement to prevention and treatment of PPH. It has been proved to reduce blood loss in elective surgery, bleeding in trauma patients, and menstrual blood loss.
\end{abstract}

Aims: To evaluate the effectiveness of TXA in reducing blood loss given just immediately after delivery of baby in women undergoing cesarean section.

Methods: This was a prospective, randomized, double blind, placebo controlled study conducted in the Department of Gynaecology and Obstetrics unit of IBN SINA Medical College Dhaka, Bangladesh from June 2016 to May 2017. Participants were randomly assigned to TXA group or group $A(n=60)$ and placebo group or group $B(n=60)$. Randomization was done by residents using computer generated random numbers. Group A received $1 \mathrm{gram}$ $(10 \mathrm{ml})$ of intravenous bolus dose of TXA just after delivery of the baby, Group B received 10 $\mathrm{ml}$ of sterile distilled water for injection intravenously at the same time. Statistical analysis has been done by SPSS.

Results: The subjective characteristics in the two groups were similar with respect to their age, BMI, gestational age and gravidity. The duration of surgery was 40-50 minutes. There was no statistically significant difference in the heart rates $(p>0.05)$ and blood pressures between the two groups, after 2 hours of delivery. Blood losses from both placental deliveries to the end of cesarean section and from end of CS to 2 hours postpartum were significantly lower in the study group $(p<0.05)$. Change in hemoglobin concentration in study group was also significantly less than in the control group. Total amount of oxytocin required was significantly less in TXA group $(p<0.05)$ also the number of women requiring other oxytocics (inj. Methyl ergometrine, inj carboprost and tab misoprostol per rectally) was significantly less in TXA group $(p<0.05)$. The amount of intra-operative fluid required were significantly less in TXA group ( $p<0.005)$; however post - operative fluid requirement and minor side effects in the form of nausea and vomiting were similar in both the groups.

Conclusion: Tranexamic acid can effectively reduce blood loss in patients undergoing LSCS and its use was not associated with any side effects and or complications like thrombosis. The adoption of $W H O$ guidelines for using uterotonic agents and prophylactically administering TXA may significantly reduce the number of PPH incidents.

Key words: Tranexamic Acid, Caesarean Section, Postpartum haemorrhage.

Introduction:

Primary post partum hemorrhage (PPH) is a major cause of maternal mortality, accounting for close to one quarter of all maternal deaths worldwide ${ }^{(1)}$. Most of the deaths occur soon after giving birth and almost all $99 \%$ occur in low- income and middle income

1. Associate Professor, Department of Obstetrics and Gynaecololgy, Ibn Sina Medical College \& Hospital, Dhaka

2. Professor and Head of the Department of Obstetrics and Gynaecololgy, Ibn Sina Medical College \& Hospital, Dhaka.

Address of Correspondence: Dr. Nazlima Nargis, Associate Professor, Department of Obstetrics and Gynaecololgy Ibn Sina Medical College \& Hospital, Mobile no. 01718417441, e-mail: nazlimanargis@gmail.com 
countries $^{(2)}$. Primary postpartum hemorrhage $(\mathrm{PPH})$ is classically defined as blood loss of $>500 \mathrm{ml}$ for a vaginal delivery and $>1000 \mathrm{ml}$ for a cesarean delivery in the first 24 hours after delivery ${ }^{(3)}$. Recently caesarean section (CS) rates have increased to as high as $25-30 \%$ in many areas of the world. In Bangladesh, the CS rate is $23 \%{ }^{(4)}$. Delivery by CS can cause more complications than normal vaginal delivery and one of the most common complications is primary or secondary postpartum haemorrhage $(20 \%)^{(5)}$. Obstetric hemorrhage can be life threatening, therefore, to reduce the morbidity and mortality due to obstetric haemorrhage we need to reduce the bleeding at caesarean sections.

Tranexamic acid (TXA) is a synthetic derivative of the amino acid lysine that exerts its antifibrinolytic effect through the reversible blockade of the lysine binding sites on plasminogen molecules ${ }^{(6)}$. Intravenous administration of tranexamic acid has been routinely used for many years to reduce hemorrhage during and after surgical procedures like coronary artery bypass, scoliosis surgery, oral surgery, orthotopic liver transplantation, total hip or knee arthroplasty, and urinary tract surgery $(7,8)$. TXA has been shown to be very useful in reducing blood loss and incidence of blood transfusion in these surgeries.

The aim of this study was to evaluate the effectiveness of TXA in reducing blood loss given immediately just after delivery of the baby in women undergoing cesarean section.

\section{Methodology}

This was a prospective, randomized, double blind, placebo controlled study conducted in the Department of Gynaecology and Obstetrics unit of IBN SINA Medical college Dhaka, Bangladesh from June 2016 to May 2017.

Inclusion criteria were age $>18$ years, term $>35$ wks of gestation, singleton pregnancy, elective cesarean section and providing informed written consent.

Exclusion criteria were history of venous (deep vein thrombosis and /or pulmonary embolism) or arterial (angina pectoris, myocardial infarction, stroke ) thrombosis, history of epilepsy or seizure, any known cardiovascular ,renal or liver disorders, autoimmune disease, sickle cell disease, severe hemorrhagic disease, placenta praevia, abnormally invasive placenta (placenta accreta/ increta/ percreta), abruptioplacenta, eclampsia, HELLP syndrome, multiple pregnancy, In utero fetal death and administration of low molecular weight heparin or antiplatelet agents before delivery.

The participants who fulfilled the eligibility criteria were explained about the study with special reference to the beneficial and possible adverse effects of intravenous tranexamic acid. The study was approved by the independent Ethics Committee of this institute. Participants were randomly assigned to TXA group or Group A $(n=60)$ and placebo group or Group B $(n=60)$. Randomization was done by residents using computer generated random numbers. Group A received 1 gram $(10 \mathrm{ml})$ of intravenous bolus dose of TXA just after delivery of the baby, group $B$ received $10 \mathrm{ml}$ of sterile distilled water for injection intravenously at the same time.

Both the patients and the investigators remained blinded to the group assignment. The injecions were given by a third person. All patients also received 10 units of oxytocin during the first 4 hours post operatively. Additional uterotonics in the form of oxytocin infusion, inj methylergometrine, inj.carboprost and tab misoprostol $600 \mathrm{mcg}$ per rectally were given as and when needed. All LSCS were done under spinal anaesthesia.

\section{Primary outcome measures were-}

1. Heart rate, respiratory rate, blood pressure were checked and noted before the surgery, immediately after placental delivery and 1 and 2 hours after birth, respectively .

2. Blood loss from delivery of the placenta to the end of the cesarean section which was measured by adding the volume of the contents of the suction bottle which was changed after delivery of placenta to avoid being mixed with amniotic fluid and blood from parities and the difference in weight (in grams) between the dry and the soaked operation sheets, gauze pieces and mops (1 gram is equivalent to $1 \mathrm{ml}$ ).

3. Blood loss from the end of CS to 2 hours postpartum which was measured by weighing the soaked pads (in grams) and subtracting the weight of dry pads (in grams) from it (I gram is equivalent to $1 \mathrm{ml})^{9}$.

4. Hemoglobin estimation was done in all patients preoperatively and 24 hours post operatively and the change in concentration was noted. 
Secondary outcome measures were need for additional uterotonic, use of additional surgical intervention to control post partum hemorrhage, the amount of fluid infused, need for blood transfusion, mild side effects such as nausea, vomiting, headache, skin reactions and maternal death or severe maternal morbidity such as seizure, thromboembolic events, need for intensive care unit admission, hysterectomy.

Statistical analysis has been done by SPSS 22.0. Mean and standard deviations were calculated for continous variable like age, weight, height in meters and gestational age for both placebo and TXA. Independent sample t-test was used to find the significant difference. Two sample paired $t$ - test was also used to find the difference between hemoglobin (pre and postoperatively) and hematocrit (pre and postoperatively) variables, and independent sample t-test was used to find the relationship between placental delivery to the end of CS among placebo and TXA. Level of significance in terms of $p$-value was considered as $p<0.05$.

\section{Results:}

The subjective characteristics in the two groups were similar with respect to their age, BMI, gestational age and gravidity (Table-I) with no statistically significant significance. All LSCS were done under spinal anaesthesia. The duration of surgery was $40-50$ minutes in $50 \%$ cases. There was no statistically significant difference in the heart rates $(p>0.05)$ and blood pressures between the two groups, after 2 hours of delivery (Table-II). Blood losses from both placental deliveries to the end of caesarean section and from end of CS to 2 hours postpartum were significantly lower in the study group $(p<0.05)$ (Table III).

Change in hemoglobin concentration in study group was also significantly less than in the control group (Table III). Total amount of oxytocin required was significantly less in TXA group $(p<0.05)$ also the number of women requiring other oxytocics (inj. Methyl ergometrine, inj carboprost and tab misoprostol per rectally) was significantly less in TXA group $(p<0.05)$. Neither group required any additional surgical intervention to control PPH. The amount of intra-operative fluid required were significantly less in TXA group ( $p<0.005)$. However postoperative fluid requirement was comparable in both the groups $(p>0.05)$. Minor side effects in the form of nausea and vomiting were comparable in both the groups (Table III). No major side effect was observed in either

Table-I

Demographic Variables in study and control groups $(N=120)$

\begin{tabular}{lccc}
\hline Variables & $\begin{array}{c}\text { Study group } \\
(\mathrm{n}=60) \text { mean } \pm \mathrm{SD}\end{array}$ & $\begin{array}{c}\text { Placebo group } \\
(\mathrm{n}=60) \text { mean } \pm \mathrm{SD}\end{array}$ & P-value \\
\hline Maternal age (years) & $25.34 \pm 3.8$ & $25.68 \pm 3.3$ & $0.602^{\mathrm{ns}}$ \\
Weight $(\mathrm{kg})$ & $66.56 \pm 5.03$ & $67.5 \pm 3.4$ & $0.234^{\mathrm{ns}}$ \\
Gestational age (weeks) & $38.84 \pm 1.28$ & $38.6 \pm 1.67$ & $0.379^{\mathrm{ns}}$ \\
Gravidity & $2.1 \pm 1.002$ & $2.09 \pm 0.73$ & $0.950 \mathrm{~ns}$ \\
\hline
\end{tabular}

$P$ value reached from Unpaired student t-test, ns $=$ not significant

Table-II

Vital signs after placenta delivery in study \& control groups ( $n=120)$

\begin{tabular}{|c|c|c|c|c|c|c|c|c|c|}
\hline \multirow[t]{2}{*}{ Vital signs } & \multicolumn{3}{|c|}{$\begin{array}{c}\text { Immediate after placenta } \\
\text { delivery }\end{array}$} & \multicolumn{3}{|c|}{$\begin{array}{c}1 \text { hour after placenta } \\
\text { delivery }\end{array}$} & \multicolumn{3}{|c|}{$\begin{array}{c}2 \text { hours after placenta } \\
\text { delivery }\end{array}$} \\
\hline & Study & Control & P-value & Study & Control & P-value & Study & Control & P-value \\
\hline Heart & $90.31 \pm 22.8$ & $91.45 \pm 7.60$ & 0.714 & $91.13 \pm 8.41$ & $88.71 \pm 7.84$ & 0.106 & $88.62 \pm 4.7$ & $88.11 \pm 3.7$ & $0.520^{\mathrm{ns}}$ \\
\hline Resp.rate(breath/min) & $18.67 \pm 0.51$ & $19.05 \pm 4.81$ & 0.544 & $18.45 \pm 0.32$ & $18.35 \pm 0.27$ & 0.071 & $18.13 \pm 0.91$ & $18.47 \pm 1.12$ & $0.071^{\mathrm{ns}}$ \\
\hline Systolic BPMean (mm Hg) & $122.51 \pm 10.56$ & $125.24 \pm 8.26$ & 0.117 & $131.76 \pm 12.16$ & $127.69 \pm 11.78$ & 0.065 & $123.48 \pm 7.85$ & $123.60 \pm 8.64$ & $0.936^{\mathrm{ns}}$ \\
\hline Diastolic BPMean $(\mathrm{mm} \mathrm{Hg})$ & $75.41 \pm 10.8$ & $78.56 \pm 9.64$ & 0.095 & $77.52 \pm 8.37$ & $75.8 \pm 11.58$ & 0.353 & $76.21 \pm 6.28$ & $73.25 \pm 11.5$ & $0.083^{\mathrm{ns}}$ \\
\hline
\end{tabular}

$\mathrm{P}$ value reached from Unpaired student $\mathrm{t}$-test, $\mathrm{ns}=$ not significant 
Table-III

Operative and post operative variables in study and control groups

\begin{tabular}{|c|c|c|c|}
\hline Variables & $\begin{array}{c}\text { Study group } \\
(\mathrm{n}=60) \text { mean } \pm S D\end{array}$ & $\begin{array}{c}\text { Placebo group } \\
(\mathrm{n}=60) \text { mean } \pm \mathrm{SD}\end{array}$ & P- value \\
\hline Surgery duration (minutes) & $41.35 \pm 6.285$ & $42.6 \pm 5.132$ & $0.235^{\mathrm{ns}}$ \\
\hline Blood loss from placental delivery to the end of $\mathrm{C} / \mathrm{S}(\mathrm{ml})$ & $358.8 \pm 28.87$ & $615.8 \pm 95.23$ & $<0.001^{*}$ \\
\hline Blood loss from end of C/S to 2 hours post partum (ml) & $51.06 \pm 7.35$ & $77.03 \pm 5.20$ & $<0.001^{*}$ \\
\hline Change in $\mathrm{Hb} \%(\mathrm{gm} / \mathrm{dl})$ & $0.98 \pm 0.231$ & $1.5 \pm 0.267$ & $<0.001^{*}$ \\
\hline Oxytocin administered(units) & $30 \pm 2.8$ & $40 \pm 2.7$ & $<0.001^{*}$ \\
\hline Number of patients requiring other uterotonics ${ }^{\#}$ & $10(16.7 \%$ & $24(40.0 \%)$ & $0.005^{*}$ \\
\hline Intra-operative fluid administered(ml) & $2000 \pm 300$ & $2500 \pm 300$ & $<0.001^{*}$ \\
\hline Post-operative fluid administered(ml) & $1500 \pm 300$ & $1600 \pm 300$ & $0.070^{\mathrm{ns}}$ \\
\hline Number of patients with minor side effects $\#$ & $4(6.7 \%)$ & $4(6.7 \%)$ & $1.000 \mathrm{~ns}$ \\
\hline
\end{tabular}

$P$ value reached from Unpaired student t-test, ns=not significant ${ }^{*}$ significant

\#Chi-square test,

group. Three mothers of the control group were given blood transfusion post operatively for postpartum hemorrhage.

\section{Discussion:}

Tranexamic acid exerts its antifibrinolytic effect by blocking the lysine-binding locus of the plasminogen and plasmin molecules, thereby preventing the binding of plasminogen and plasmin to the fibrin substrate. TXA also inhibits the conversion of plasminogen to plasmin by the plasminogen activators. TXA is a potent inhibitor of fibrinolysis was first reported by Okamoto in $1962^{(10)}$. Since then, TXA has been widely used to treat heavy menstrual bleeding ${ }^{(11)}$ and to reduce blood loss in elective surgery where it reduces blood transfusion by about one third(12,13). More recently, the Clinical Randomization of an Antifibrinolytic in Significant Haemorrhage (CRASH-2) trial has shown that the early administration of TXA significantly reduces mortality in bleeding trauma patients $(14,15)$. Indeed, on the basis of the results of the CRASH -2 trial, TXA has been included in the WHO list of essential medicines $^{(16)}$. It has been used for the treatment of various types of bleeding for many tears e.g. menorrhagia, postoperatively or intraoperatively ${ }^{(17,18)}$.

During placental delivery, fibrinogen and fibrin are rapidly degraded, whereas plasminogen activators and fibrin degradation products (FDP) increase due to activation of the fibrinolytic system. This activation can last upto 6-10 hours postpartum, causing more bleeding $^{(19)}$. It was because of this activation of the fibrinolytic system that we decided to use tranexamic acid in this trial.

This study was a double blind placebo controlled trial which showed that TXA significantly reduced bleeding from the time of placental delivery to two hours postpartum in LSCS. This study shows significant decrease in the bleeding volume in TXA group as compared with the placebo group. Similar study carried out in India by Mayur et al ${ }^{(13)}$ showed comparable results reducing the blood loss in the study group. Another study carried out by Ming-Ying et al, in China showed that TXA significantly reduces bleeding from the time of placental delivery to the end of CS, which was $351 \mathrm{ml}$ in the study group while $440 \mathrm{ml}$ in the controle group ${ }^{(19)}$. Zheng et al. showed similar results after vaginal delivery. ${ }^{(20)}$ Post operative $\mathrm{Hb} \%$ was also found to be significantly higher in tranexamic acid treated group (21).

There was no significant alteration in the vital sgns of subjects following TXA administration. There were no abnormalities in liver and renal function tests and urine analysis. All the neonates had good APGARS at birth. The incidence of thrombosis during pregnancy and puerperium is 5-6 times higher than that in the general population (22). When the antifibrinolytic drug tranexamic acid is administered, the increased risk of post partum thrombosis after LSCS should be considered. In the present study, not a single patient developed thrombosis and incidences of side effects like nausea, vomiting and diarrhea were not statistically significant by difference in the two groups, these have been corroborated by other studies (19-22). 


\section{Conclusion:}

Tranexamic acid can effectively reduce blood loss in patients undergoing LSCS and its use was not associated with any side effects and or complications like thrombosis. The adoption of $\mathrm{WHO}$ guidelines for using uterotonic agents and prophylactically administering TXA may significantly reduce the number of PPH incidents.

\section{References:}

1. Sentilhes L,Lasocki S Ducloy-Bouthors AS, Deruelle P, Dreyfus M, Perrotin F, and Deneux -Tharaux C. Tranexamic acid for the prevention and treatment of post partum haemorrhage. $\mathrm{Br}$ J Anaesth.2015;114:576-87.

2. Say L, Chou D, Gemmill A,et al, Global causes of maternal death : a WHO systematic analysis. Lancet Glob Health 2014; 2: e323-33.

3. World Health Organization. Managing complications in pregnancy and childbirth. Geneva, Switzerland: World Health Organization. 2000./pdf

4. Khan MN, Islam MM, Sharif AA, Alam MM, Rahman MM. Sociodemografic predictors and average annual rates of Cesarean Section in Bangladesh between 2004 and 2014. Published: May11,2017. https://doi.org/10.1371/ journal. pone. 0177579.

5. Lu MC, Fridman M, Korst LM, Gregory KD, Reyes C, Hobel CJ, at al, Variations in the incidence of postpartum haemorrhage across hospitals in California. Matern Child Health J 2005;9:297-306.

6. Thorsen S, Clemmenson I, Sottrup-Jensen L et al. Adsorption to fibrin of native fragments of known primary structure from human plasminogen. Biochim Biohys Acta 1981;668:377-87.

7. Brown RS, Thwaites BK, Mongan PD, Tranaxamic acid is effective in decreasing postoperative bleeding and transfusions in primary coronary artery bypass operations: a double blind, randomized, placebo controlled trial, Anesth Analg, J Obstet Gynecol 1997;85:963-70

8. Ido K,Neo M,Asada Y et al. Reduction of blood loss using tranexamic acid in total knee hip arthroplasties. Arch orthop Trauma Surg. 2000; 120:518-20

9. Quantification of blood loss: AWHONN Practice Brief Number 1, JOGNN 2015;44(1):158-160.

10. Roberts I. Tranexamic acid : a recipe for saving lives in traumatic bleeding. J Tehran Heart Cent 2011;6:178

11. Lukes AS,Kouides PA, Moore KA. Tranaxamic acid : a novel oral formulation for the treatment of heavy menstrual bleeding. Womens Health 2011; 7:151-8

12. Caglar GS, Tasci $Y$, Kayikcioglu F,Haberal A. Intravenous tranexamic acid use in myomectomy: a prospective randomized double blind placebo controlled study. Eur J Obstet Gynecol Reprod Biol 2008;137:227-31. Epub 2007 May 11.

13. Mayur G, Purvi P,Ashoo G, Pankaj D. Efficacy of tranexamic acid in decreasing blood loss during and after caesarean section: a randomized case controlled prospective study. J Obstet Gynecol India 2007;57 : 227 -30.

14. CRASH -2collaborators, Shakur H, Roberts I ,Bautista R., Caballero J, Coats T, et al. Effects of tranexamic acid on death, vascular occlusive events, and blood transfusion in trauma patients with significant haemorrhage (CRASH-2): a randomized placebo controlled trial. Lancet 2010;376:23-32. Epub 2010 June 14.

15. CRASH -2 collaborators, Roberts I, Shakur $\mathrm{H}$, Afolabi a, Brohi K, Coats T ET AL. The importance of early treatment with tranexamic acid in bleeding trauma patients : an exploratory analysis of the CRASH -2 randomised controlled trial. Lancet 2011; 377: 1096-101.

16. CRASH-2collaborators; Guerriero C,Caims J, Perel P, Shakur H, Roberts I. Costeffectiveness analysis of administering tranexamic acid to bleeding trauma patients using evidence from the CRASH-2 trial . Plos One 2011;6:e 18987.

17. Gungorduk K, Yildrim G, Asicioglu O, Gunngorduk OC, Sudolmus S, Ark C. Efficacy of intravenous tranexamic acid in reducing blood loss after elective caesarean section: a prospective, randomized, double blind, placebo controlled study. Am J Perinatal 2011;28:23340. Epub 2010 Oct 26. 
18. Wong J, El Beheiry H, Rampersaud YR, Lewis $\mathrm{S}$,Ahn $\mathrm{H}$, De Silva $\mathrm{Y}$, et al. Tranexamic acid reduces perioperative blood loss in adult patients having spinal fusion surgery. Anesth Anag 2008;107:1479-86.

19. Gai MY,Wu LF, QF, Tatsumoto K. Clinical observation of blood loss reduced by tranexamic acid during and after cesarean section: a multicentre randomized trial. Eur J Obstet Gynecol Reprod Biol 2004; 112: 154-7.

20. Yang $\mathrm{H}$, Zheng S, Shi C. Clinical study on the efficacy of tranexamic acid in reducing postpartum blood loss: a randomized ,comparative, multicentre trial .Chin J Obstet Gynecol 2001;36:590-2.

21. Sekhavat L, Tabatabaii A, Dalili M, Farajkhoda $T$, Tafti AD. Efficacy of tranexamic acid in reducing blood loss after cesarean section. $J$ Matern Fetal Neonatal Med .2009 Jan;22 (1): 72-5.

22. Lindoff C, Rybo G, Astedt B. Treatment with tranexamic acid during pregnancy, and the risk of thrombo-embolic complications. Throm Haemost. 1993;70 : 238-40. 